\title{
PEDAGOGÍA Y EMANCIPACIONES EN LA VENEZUELA BOLIVARIANA: LA POLÍTICA EDUCATIVA PARA EL SOCIALISMO DEL SIGLO XXI
}

\author{
PABLO IMEN*
}

RESUMEN: Este artículo analiza el proceso de desarrollo social, político y educativo en Venezuela. A partir de una perspectiva histórica se describen los principales lineamientos de la política educativa del socialismo bolivariano abordando los supuestos, valores, dispositivos, herramientas y orientación proporcionados por el actual gobierno. Luego se analizan la evolución, las tensiones, contradicciones y obstáculos para la construcción de un modelo pedagógico emancipador. Finalmente se proponen algunas reflexiones teóricas y prácticas sobre el proceso analizado.

Palabras clave: Transición revolucionaria. Educación emancipadora. Política educacional. Relaciones pedagógicas. Avances y resistencias.

\section{Pedagogy and emancipations in bolivarian Venezuela:} EDUCATION POLICIES FOR THE $20^{\text {TH }}$ CENTURY SOCIALISM

ABSTRACT: This paper analyzes the social, political and educational development process in Venezuela. From a historical perspective, it describes the main lines of the education policies of the Bolivarian Socialism through the assumptions, values, devices, tools and guidance provided by the current government. It then analyzes how the construction of this emancipatory pedagogical model has evolved and the tensions, contradictions and obstacles it has to overcome. It finally proposes theoretical and practical reflections on the analyzed process.

Key words: Revolutionary transition. Emancipatory education. Education policies. Pedagogical pelations. Progress and resistance.

\section{Pédagogie et emancipations au Venezuela bolivarien: LA POLITIQUE ÉDUCATIVE POUR LE SOCIALISME DU XXI ${ }^{\mathrm{E}}$ SIÈCLE}

RÉSUMÉ: Cet article analyse le processus de développement social, politique et éducatif au Venezuela. Il décrit les principales lignes de la politique éducative du socialisme bolivarien dans une perspective historique, en abordant les

Maestrando en Política y Gestión de la Educación, en la Universidad Nacional de Luján, y secretario de Investigaciones del Centro Cultural de la Cooperación Floreal Gorini. E-mail: pabloadrianimen@gmail.com 
valeurs, dispositifs, outils et orientations fournis par le gouvernement actuel. Il commence par analyser l'évolution, les tensions, les contradictions et les obstacles qui ont jalonné la construction d'un modèle pédagogique émancipateur. Finalement il propose quelques réflexions théoriques et pratiques sur le processus analysé.

Mots-clés: Transition révolutionnaire. Éducation émancipatrice. Politique éducationnelle. Relations pédagogiques. Avances et résistances.

$\mathrm{V}$ enezuela asumió, a partir de 1998, el desafío de construir el socialismo bolivariano e impulsar un proceso de unidad de Nuestra América. Es en este contexto específico en que deben comprenderse las políticas públicas en general y la educativa en particular.

En este trabajo nos proponemos describir algunas de las líneas directrices del modelo educativo consistente con el nuevo orden en gestación y reflexionar acerca de algunas referencias a prácticas prefigurativas de una educación pública en construcción y en disputa.

El proceso está en desarrollo, las formas nuevas que se van creando e implantando tienen un estado germinal, de manera que el escrito tiene una provisoriedad adicional a cualquier texto que se proponga "objetivar" la realidad: hablamos de unos discursos, unas prácticas, unas estructuras y unas relaciones que están en estado de permanente revisión, recreación, reformulación. Claro que esta dinámica de cambios no ocurre de manera antojadiza sino doblemente enmarcada. Primero, orientada por el horizonte del socialismo según las peculiares características que asume en el contexto venezolano. Segundo, por unos principios políticos, culturales y pedagógicos que constituyen una suerte de brújula desde la cual ensayar y revisar las novedades en el sistema educativo.

Como toda construcción inédita, es compleja y con muchas aristas, donde se producen tensiones entre los intentos de cambios estructurales y la reproducción del orden hegemónico. Surgen propuestas de múltiples sujetos, estimulados desde el Estado que ha definido constitucionalmente (y por la vía más concreta de los hechos) forjar una democracia protagónica y participativa como reemplazo de la democracia representativa que representó al modelo capitalista preexistente.

Es preciso en este marco señalar que el elemento subjetivo juega un papel fundamental. El discurso oficial remite a la exigencia de una batalla cultural por la difusión, apropiación y recreación de nuevos valores fundados en la igualdad, la emancipación, la solidaridad, la justicia, la participación, la democracia sustantiva constituye un objetivo de largo aliento y requisito para el logro de las transformaciones revolucionarias en curso. La coexistencia del viejo sentido común y la emergencia del nuevo sentido común - de orientación humanista - tensiona los cambios. 
Según las fuentes relevadas, habría necesidad de propiciar procesos de formación y acompañamiento para la construcción de la nueva educación pública, desde la problematización filosófica, axiológica, metodológica y epistemológica, que sea consistente con los planteamientos que establece la Constitución de la República Boliviariana de Venezuela (CRBv); el Proyecto Nacional de Desarrollo Simón Bolívar (PNDSB) y la Ley Orgánica de Educación (LOE).

En el trabajo haremos una exposición sumaria de las orientaciones generales a las que nos referimos en las citadas CRBV, PNDSB y LOE.

En las conclusiones desplegaremos algunas reflexiones políticas, teóricas y metodológicas sobre el camino emprendido por la Venezuela Bolivariana, que transita momentos intensos de creación y sobre cuyo presente y futuro se vislumbran logros tangibles así como urgentes incertidumbres y complejos interrogantes, dada la magnitud de la empresa emprendida.

\section{La política pública en tiempos de transición: de la IV República al Socialismo Bolivariano}

La LOE expresa las orientaciones fundamentales de la actual política educativa. Pero es preciso antes de abordarla comprender la historia social y política que hizo posible este cambio en la sociedad y en la educación.

El gobierno de Carlos Andrés Pérez desplegó políticas públicas fundadas en el Consenso de Washington, algunas de cuyas consecuencias se expresaron en altos niveles de pobreza extrema, inflación, exclusión, explotación, con tendencias hacia la privatización del espacio público, como ocurrió con el caso concreto la educación.

El fenómeno conocido como el Caracazo fue un levantamiento popular desatado en febrero de 1989 como prólogo de la caída de la iv República. ${ }^{1}$ Frente al establecimiento de medidas de ajuste impulsadas por el gobierno de Carlos Andrés Pérez hubo una movilización espontánea de los sectores populares. El levantamiento fue reprimido brutalmente por las fuerzas de seguridad.

Las políticas públicas neoliberales promovidas por el FMI, el Banco Mundial y el BID agudizaron la desigualdad y acentuaron la dependencia de modelos exógenos. En el campo educativo se repitió esa adopción de métodos, contenidos y formas de orientación tecnocrática.

Las luchas de resistencia social, política, cultural y pedagógica en Venezuela, desde 1989, abonaron el terreno para la emergencia de nuevas condiciones políticas.

En el año 1998, se comienzan a gestar nuevas formas organizativas que se pondrán en funcionamiento con el triunfo electoral de Hugo Chávez. Tal es el caso 
de Frentes Sectoriales como estructuras específicas para construir propuestas de gobierno para la etapa refundacional que se inicia entonces en el país. En el caso que nos ocupa, el Frente de Educadores se conformó con el aporte del movimiento pedagógico preexistente, que se desarrolló desde fines de los años ochenta, especialmente en los Estados de Lara y de Aragua, creciendo exponencialmente a partir de la elección presidencial de 1998.

En "Educación para la vida y la libertad" se vuelcan los planteos que desde hace más de 15 años venían ensayando los docentes organizados dentro de las escuelas públicas. Este documento recoge el sentir de los docentes autodenominados "insurgentes" presentándose como propuesta para una educación liberadora y como brújula para una nueva política educativa.

Entre $1999^{2}$ y 2001 se desarrolló un proceso de consulta popular, denominado Constituyente Educativa. Tuvo una dinámica de amplia participación y tuvo como corolario la elaboración del Proyecto Educativo Nacional (PEN), que constituye una propuesta que el gobierno asume como línea directriz de la política educativa.

Hacia el final de la primera gestión del ministro Héctor Navarro (2001-2002), se comienza a plasmar la propuesta de crear las denominadas Misiones Educativas. Se trata de un nuevo tipo de institucionalidad que tiene como fin la inclusión de los sectores populares - tradicionalmente privados del derecho a la educación - a los distintos niveles del sistema educativo. Dichas Misiones van instrumentándose de manera paralela a las instituciones escolares tradicionales. ${ }^{3}$ De su creación pueden señalarse dos cosas. Primero, que la invención de esta nueva institucionalidad apuntó a superar la incapacidad de las escuelas tradicionales para incorporar a los sectores populares en su seno y garantizar concretamente el derecho a la educación, consagrado en la Constitución de la República Bolivariana de Venezuela como un derecho humano.

La segunda cuestión remite a un desafío no menos complejo. Se esperaba de las instituciones bolivarianas la invención de una educación emancipadora. Esta fue la primera iniciativa frente a la educación pública tradicional, a menudo reproductora de relaciones, procesos, estructuras y prácticas para la desigualdad, la imposición y la negación de la diferencia.

Luego de una década de experiencia, se consolidaron en y desde la educación bolivariana algunos lineamientos de la nueva educación pública que se reflejaron en la LOE, sancionada diez años después de la Constituyente Educativa originaria. Tal vez ese sea el elemento que permita afirmar que la LOE, según los propios docentes, es el producto de una creación colectiva. Así nos relata un docente este particular modo de construcción de la política educativa bolivariana:

Ud. habló de la Ley Orgánica de Educación, vio lo bonita que es... pero la Ley Orgánica de Educación es de reciente data... Nosotros somos Liceos Bolivarianos desde antes que 
naciera la Ley Orgánica de Educación... o sea, es un proceso completamente distinto a los anteriores... Antes aquí en la educación se cambiaba el reglamento, el patrón y después se los llevaba a los docentes para que nosotros lo aplicáramos... Aquí en cambio nos permitieron a nosotros experimentar, transformar la realidad, ver como nosotros desde nuestros espacios podíamos mejorar el sistema educativo y después de eso es que la Ley Orgánica se adoptó... o sea que cuando leemos la Ley Orgánica nos vemos reflejados allí, porque prácticamente lo que está allí escrito es el día a día de lo que nosotros hacemos. Fue un proceso intenso pero ha dado resultado. ${ }^{4}$

\section{El orden en construcción y las nuevas regulaciones}

La Constitución Bolivariana introduce transformaciones fundamentales en la organización de la sociedad heredada del modelo neoliberal. Concibe al Estado como garante de derechos, promueve una democracia protagónica y participativa, valoriza la educación y al trabajo liberador como ejes centrales de un nuevo orden social a construir. El intento de reforma constitucional de 2007 fue derrotado en un referéndum por escaso margen, y ya explicitaba la definición del socialismo bolivariano.

La voluntad de construir este nuevo orden tiene implicancias mediatas e inmediatas para el Sistema Educativo. Una batería de leyes son la continuación jurídico-política de iniciativas colectivas que apuntan a fundar una nueva economía y una nueva ciudadanía, refundando el espacio de lo público, creando nuevas instituciones, mutando las viejas, todo ello no sin contradicciones y complejidades.

La transición entraña una coexistencia entre la vieja y la nueva sociedad, en un proceso que combina la simultaneidad de instituciones, estructuras, prácticas y relaciones. Ocurre en todos los aspectos de la vida social: en la economía, en la organización territorial, también educativa. Veámoslo sumariamente.

En la disputa por la creación de un orden socialista se inscriben las experiencias de Empresas Autogestionadas, Empresas Socialistas avanzando en la generación de unas nuevas relaciones productivas que luchan a brazo partido con las entidades heredadas y aún hegemónicas de la economía capitalista.

En la organización territorial también conviven de modo conflictivo lo viejo y lo nuevo. En tal sentido, las instituciones de la democracia representativa son escenario de intensas disputas para adecuar las tradicionales estructuras político-administrativas a las exigencias de una democracia protagónica y participativa. En simultáneo, se va generando una nueva institucionalidad que se agrupa bajo la denominación de Consejos Comunales y Comunas que van planteando nuevos modos de gestión de lo público. ${ }^{5}$ Todo el entramado de instituciones comunitarias despliega una creciente participación popular en la vida social, es decir, los consejos comunales y las comunas. Y su relación con las instancias tradicionales de la organización político-administrativa - parroquias, municipios, gobernaciones - es compleja y contradictoria. 
Si un foco nos conduce a la creación de nuevas instituciones, otro aspecto a considerar es la trasformación de las viejas estructuras institucionales. Así ocurre con la función legislativa, configurándose un dispositivo que, en palabras oficiales, remite a la concepción de "pueblo legislador". Ya lo vimos con la educación, una esfera en la cual antes de sancionar la nueva legislación se experimentaron durante una década larga propuestas generadas en el propio sistema educativo.

¿Cuál es el Proyecto que va organizando estas experiencias, resistidas de modo brutal por las viejas clases dominantes? ${ }^{6}$ El Proyecto Nacional Simón Bolívar, que rige para el período 2007-2013, se plantea explícitamente que "En este período (...) se orienta Venezuela hacia la construcción del Socialismo del Siglo XXI". ${ }^{7}$

Esa nueva forma de gestión de lo público va dando lugar a leyes que van consolidando esas experiencias: Leyes Orgánicas de Poder Popular; de Consejos Comunales, del Sistema Económico Comunal, de Planificación Pública y Popular, de Contraloría Social; de Comunas y del Consejo Federal de Gobierno. Dichas normas constituyen verdaderos blindajes jurídicos para impulsar las experiencias transformadoras que se dan en el ámbito de la producción, el Estado y la política. El resultado es la expansión, profundización y ampliación del espacio público. Según informó el Ministerio del Poder Popular para las Comunas, hay ya funcionando aproximadamente 42.000 Consejos Comunales en Venezuela, y unos 45.000 proyectos de obras se han canalizado en el territorio nacional por esta vía.

Pues bien, esta reconfiguración de inspiración socialista se expresa en la propia Loe.

\section{Contenidos fundamentales de la Ley Orgánica de Educación}

En el primer artículo de la norma queda planteado el impulso de acciones, por parte del Estado Nacional, tendientes a "desarrollar los principios y valores rectores, derechos, garantías, deberes en educación, que asume el Estado como función indeclinable y de máximo interés (...) para la transformación social".

En el artículo $3^{\circ}$ se introducen ya definiciones de gran densidad política. Allí se "establece que la educación es pública y social, obligatoria, gratuita, de calidad, de carácter laico, integral, permanente, con pertinencia social, creativa, artística, innovadora, crítica, pluricultural, multiétnica, intercultural, y plurilingüe". El artículo $4^{\mathrm{o}}$ define a la educación:

(...) como derecho humano y deber social fundamental orientada al desarrollo del potencial creativo de cada ser humano en condiciones históricamente determinadas, constituye el eje central de la creación, transmisión y reproducción de las diversas manifestaciones 
y valores culturales, invenciones, expresiones, representaciones y características propias para apreciar, asumir y transformar la realidad. ${ }^{8}$

En simultáneo, la norma impone unos límites muy fuertes a las instituciones educativas privadas, revirtiendo un largo período de crecientes conquistas de este sector en detrimento de la educación oficial. ${ }^{9}$

También reformula las relaciones de la educación con el contexto. En efecto, se trata de "Desarrollar un proceso educativo que eleve la conciencia para alcanzar la suprema felicidad social a través de una estructura económica incluyente y un nuevo modelo productivo social, humanista y endógeno". ${ }^{10}$

La LOE define al Estado como Estado Docente, lo cual supone al menos cuatro cosas. Primero, se trata de un Estado Garante. Segundo, se trata de un Estado que puede y debe acompañar, formar, construir. Tercero, el Estado que tiene atribuciones para intervenir quebrando resistencias conservadoras a través de regulaciones e instrumentos punitivos. Y cuarto, al mismo tiempo, el propio Estado debe ser objeto de contraloría social. Dicho en otras palabras, también las políticas pueden y deben ser evaluadas.

Otro ítem de enorme significación remite a la regulación de las instancias del gobierno de la educación.

\section{Gobierno de la Educación en la LOE}

Dice el artículo $19^{\circ}$ que

El Estado, a través del órgano con competencia en el subsistema de educación básica, ejerce la orientación, la dirección estratégica y la supervisión del proceso educativo y estimula la participación comunitaria, incorporando tanto los colectivos internos de la escuela, como a diversos actores comunitarios participantes activos de la gestión escolar en las instituciones, centros y planteles educativos en lo atinente a la formación, ejecución y control de la gestión educativa bajo el principio de corresponsabilidad, de acuerdo con lo establecido en la Constitución de la República y la presente ley.

En otras palabras, el Estado - que además se compromete a un modelo de gestión eficaz y desburocratizado - se propone apuntalar procesos participativos en todos los ámbitos de la vida social y específicamente, en las instituciones educativas. La LoE defiende

La creación de una administración eficiente, efectiva, eficaz, desburocratizada, transparente e innovadora, fundamentada en los principios de democracia participativa, solidaridad, ética, honestidad, legalidad, economía, participación, corresponsabilidad, celeridad, rendición de cuentas y responsabilidad social. (Art. 6.3.j) 
Estas definiciones deben complementarse con aquellas que refieren a la participación popular en la gestión del Estado. Así la norma establece la exigencia de plasmar la participación "de las diferentes organizaciones sociales y comunitarias en el funcionamiento y gestión del Sistema Educativo, facilitando distintos mecanismos de contraloría social". La contraloría social es reivindicada como un principio de la democracia protagónica y participativa en la esfera de la educación pública - en rigor, como principio estructurante de la vida social y política - que debe ser garantizada, impulsada y sostenida por el Estado:

El Estado garantiza, a través del órgano rector con competencia en el subsistema de educación básica, la formación permanente de los ciudadanos y las ciudadanas integrantes de la comunidad educativa para efectos del cumplimiento de la contraloría social y otros deberes de los ciudadanos y las ciudadanas en la gestión educativa. (Art. 20 in fine)

Un instrumento relevante para plasmar los fines de la educación es la organización de la estructura académica bajo la cual se reordena el sistema formal. Describiremos a continuación algunos de sus elementos más significativos.

\section{Estructura académica del Sistema Educativo Venezolano}

\section{La LoE define en estos términos al Sistema Educativo Venezolano:}

El Sistema Educativo es un conjunto orgánico y estructurado, conformado por subsistemas, niveles y modalidades de acuerdo con las etapas del desarrollo humano. Se basa en los postulados de unidad, corresponsabilidad, interdependencia y flexibilidad. Integra políticas, planteles, servicios y comunidades para organizar el proceso educativo y la formación permanente de la persona sin distingo de edades, con el respeto a sus capacidades, a la diversidad étnica, lingüística y cultural, atendiendo a las necesidades y potencialidades locales, regionales y nacionales. (Art. $24^{\circ}$ )

La LoE contempla la nueva y compleja organización del Sistema Educativo Bolivariano, según lo indicado en el artículo 25․

Como parte del Sistema Educativo, los órganos rectores en materia de educación básica y de educación universitaria garantizan: a) Condiciones y oportunidades para el otorgamiento de acreditaciones y reconocimiento de aprendizajes, invenciones, experiencias y saberes ancestrales, artesanales, tradicionales y populares, de aquellas personas que no han realizado estudios académicos, de acuerdo con la respectiva reglamentación. b) el desarrollo institucional y óptimo funcionamiento de las misiones educativas para el acceso , la permanencia, prosecución y culminación de estudios de todas las personas, con el objeto de garantizar la universalización del derecho a la educación.

En síntesis, aquí vemos que la organización del Sistema Educativo se estructura a partir de las necesidades del progreso humano, atendiendo a las especificidades 
generacionales, regionales y culturales. Hay un reconocimiento de saberes que portan actores tradicionalmente excluidos de la cultura escolar. Finalmente, las Misiones son consideradas como estructuras de pleno derecho en el sistema educativo formal. Este reconocimiento anticipa un paso posterior: consolidar los avances pedagógicos de las misiones y transvasarlos a las instituciones escolares tradicionales, más resistentes a la construcción de un nuevo paradigma pedagógico.

Si estas definiciones constituyen elementos de enorme significación en la construcción del nuevo modelo educativo, la dimensión pedagógica es un eje fundamental del debate a los fines de refundar la educación pública en un sentido emancipatorio. Vamos a analizar este aspecto.

\section{La cuestión pedagógica}

El modelo educativo que se está estableciendo tiene resonancias de gran alcance en el propio proceso pedagógico. Un fragmento del artículo $14^{\circ}$ sostiene que

La educación regulada por esta ley se funda en la doctrina de nuestro Libertador Simón
Bolivar, en la doctrina de Simón Rodríguez, en el humanismo social y está abierta a todas
las corrientes del pensamiento. La didáctica está centrada en los procesos que tienen como
eje la investigación, la creatividad y la innovación, lo cual permite adecuar las estrategias,
los recursos y la organización del aula, a partir de la diversidad de intereses y necesidades
de los y las estudiantes.

Este texto muestra novedades sustantivas en el campo pedagógico.

La vida institucional tiene como centro los intereses y necesidades de los estudiantes, superándose así la noción tradicional de la cultura escolar rígida en función de la cual los "alumnos" son formateados, y premiados o castigados según su rendimiento.

La didáctica - en los términos que expresa la letra legal - no se funda en la transmisión de unos conocimientos producidos por expertos sino que reclama prácticas de investigación e innovación. Los docentes son interpelados como constructores de conocimientos y se exige que tomen una activa participación en la elaboración e implementación del currículo. Se descartan así los paquetes pedagógicos tecnocráticos para dar lugar a un modelo de trabajo docente y de relación pedagógica contextualizada, socialmente pertinente y basada en criterios participativos.

En tal sentido cobra importancia el reconocimiento legal de aquellos saberes, inquietudes y preguntas que traen los estudiantes, y en ello se incluye a los docentes y a la comunidad bajo el concepto de "diálogo de saberes". Esta perspectiva revaloriza los conocimientos de la comunidad, de los educandos, de sus familias y 
de los docentes. Desde este reconocimiento son incluidos en un modelo curricular que debe respetar y reconocer los diversos puntos de vista, integrando visiones y culturas en la relación pedagógica. Supone entonces una nueva concepción de "conocimiento legítimo", más amplio e incluyente que el currículo escolar tradicional. El artículo 15, numeral 8, reconoce el aporte del conocimiento científico al establecer la tarea de "desarrollar la capacidad de abstracción y el pensamiento crítico mediante la formación en filosofía, lógica y matemática, con métodos innovadores que privilegien el aprendizaje desde la cotidianeidad y la experiencia" (15.8).

Ahora bien, hay un artículo que tiene una particular proyección pedagógica, teórica y política que establece que el Estado planifica políticas y programas

(...) de desarrollo socio-cognitivo integral de ciudadanos y ciudadanas, articulando de forma permanente, el aprender a ser, a conocer, a hacer y a convivir, para desarrollar armónicamente los aspectos cognitivos, afectivos, axiológicos y prácticos, y superar la fragmentación, la atomización del saber y la separación entre las actividades manuales e intelectuales. (6.3.d)

Entonces el currículo ahora se orienta por otros fines, por otras formas de construcción, por su carácter integral, por una nueva articulación entre lo individual y lo colectivo, por una nueva relación entre teoría y práctica; por la integración y diálogo de saberes que contribuya a una formación omnilateral; por la construcción de una ciudadanía plena y de unos futuros productores-gobernantes... Si esto es así, entonces también debe ser diferente el sentido, el modo y los usos de la evaluación. Sobre este punto dice el artículo $44^{\circ}$ de la roe que

La evaluación como parte del proceso educativo, es democrática, participativa, continua, integral, cooperativa, sistemática, cuali-cuantitativa, diagnóstica, flexible, formativa y acumulativa. Debe apreciar y registrar de manera permanente, mediante procedimientos científicos, técnicos y humanísticos, el rendimiento estudiantil, el proceso de apropiación y construcción de los aprendizajes, tomando en cuenta los factores sociohistóricos, las diferencias individuales y valorará el desempeño del educador y la educadores y, en general, todos los elementos que constituyen dicho proceso.

Así como en el plano del currículo la LOE impulsa definiciones integradoras, en un mismo sentido se establece la exigencia de sostener relaciones imbricadas entre las instituciones educativas y la comunidad. Allí dice que es preciso "alcanzar un nuevo modelo de escuela, concebida como espacio abierto para la producción y el desarrollo endógeno, el quehacer comunitario, la formación integral, la creación y la creatividad (...)" (6.3.e). Entre las funciones referidas a la promoción de la integración y la participación social establece el mejoramiento de lazos escuela-familia-comunidad "a través de una práctica social efectiva de relaciones de cooperación, solidaridad y convivencia entre las familias, la escuela, la comunidad y la sociedad, que facilite las 
condiciones para la participación organizada en la formación, ejecución y control de la gestión educativa" (6.4.a).

La educación, así, revela (en términos discursivos) orientaciones para plasmar cambios fundamentales. $Y$ dichos cambios necesariamente deben reflejarse en la modificación del propio proceso de trabajo docente. Y por tanto, del propio enseñante.

\section{Trabajadores de la Educación en la LOE}

En referencia a los trabajadores de la educación la norma también establece una serie de definiciones sustantivas.

$\mathrm{Al}$ inicio se establece el compromiso del Estado con la idoneidad de los trabajadores. En el 6.3.d refiere a la responsabilidad estatal por la “(...) formación permanente para docentes y demás personas e instituciones que participan en la educación, ejerciendo el control de los procesos correspondientes en todas las instituciones y dependencias". Por otro lado, la política de formación docente se enuncia así en la LOE:

Es función indeclinable del Estado la formulación, regulación, seguimiento y control de gestión de las políticas de formación docente a través del órgano con competencia en materia de Educación Universitaria, en atención al perfil requerido por los niveles y modalidades del Sistema Educativo y en correspondencia con las políticas, planes, programas y proyectos educativos emanados del órgano con competencia en materia de educación básica, en el marco del desarrollo humano, endógeno y soberano del país. (Art. $37^{\circ}$ )

En un sentido convergente la norma asume la centralidad de una política de formación permanente, que define como

(...) un proceso integral continuo que mediante políticas, planes, programas y proyectos actualiza y mejora el nivel de conocimientos y desempeño de los y las responsables y los y las corresponsables en la formación de ciudadanos y ciudadanas. La formación permanente deberá garantizar el fortalecimiento de una sociedad crítica, reflexiva y participativa en el desarrollo y transformación social que exige el país. (Art. 38º)

El nuevo paradigma reclama un nuevo modelo docente adecuado a una propuesta pedagógica colectiva, dialogal, que integra conocimientos, que articula teoría y práctica, que rompe con el concepto individualista del trabajo docente, que supera la lógica fragmentaria de la disciplina impulsando la interdisciplina y la transdisciplina, etc.

Ahora bien: algunas de las instituciones formadoras - las Universidades -, siguen promoviendo un docente funcional al canon del modelo pedagógico tradicional. Nos preguntamos hasta qué punto las instituciones formadoras - esto es, las Universidades - se adecuan a estas nuevas realidades en construcción. ${ }^{11}$ 
La LOE informa de una normativa que regulará el trabajo docente, pero aparecen en el texto algunas definiciones referidas a este tópico:

\begin{abstract}
La carrera docente constituye el sistema integral de ingreso, promoción, permanencia y egreso de quién la ejerce en las instituciones educativas oficiales y privadas. En los niveles desde inicial hasta media, responde a criterios de evaluación integral de mérito académico y desempeño ético, social y educativo, de conformidad a lo establecido en la Constitución de la República. Tendrán acceso a la carrera docente quienes sean profesionales de la docencia, siendo considerados como tales los que posean el título correspondiente otorgado por instituciones de formación universitaria para formar docentes. (Art. $\left.40^{\circ}\right)^{12}$
\end{abstract}

Otro elemento significativo remite a la estabilidad laboral: "Se garantiza a los y las profesionales de la docencia, la estabilidad en el ejercicio de sus funciones profesionales, tanto en el sector oficial como en el sector privado (...) en correspondencia con los principios establecidos en la Constitución (...), en esta Ley y en la ley especial" (art. $\left.41^{\circ}\right)$.

Finalmente la LOE asegura el derecho a la jubilación, en condiciones únicas: “El personal docente adquiere el derecho a la jubilación con veinticinco años de servicio activo en la educación, con un monto del 100\% del sueldo y de conformidad con lo establecido en la ley especial" (art. $41^{\circ}$ ).

En suma, este muy rápido recorrido por la normativa vigente viene a revelar una direccionalidad que se propone desmontar la organización de la escuela capitalista. Al menos en términos de la formulación discursiva, estamos en presencia de un Estado garante, se plantea una didáctica investigativa para un currículo contextualizado y socialmente pertinente, se propone un nuevo sentido al acto pedagógico y se reformula completamente el dispositivo de la evaluación; se reconfigura el tiempo y el espacio escolar, se democratizan todos los ámbitos de gobierno, se transforma el contenido del proceso de trabajo docente, entre otros.

Si esto es así en la letra, podemos ahora repasar algunos de los avances, tensiones y debates se registran en el terreno de la concreción del modelo educativo en marcha.

\title{
A modo de conclusiones (transitorias) sobre la educación Boliva- riana en Venezuela
}

En este trabajo pudimos relevar las principales orientaciones de la política educativa en Venezuela.

El trabajo de campo - cuya descripción excede los límites de este artículo - permitió registrar avances en la educación que el Estado nacional promueve y, al mismo tiempo, las luchas entre las fuerzas que impulsan los cambios contra las que 
se resisten a los mismos. Pudimos observar que hay una persistencia parcial pero aún tangible de la vieja institucionalidad pedagógica. Aunque en gradual retirada, subsisten estructuras y relaciones cuestionadas, mecanismos de injusticia en la redistribución, el (no) reconocimiento y la jerarquía autoritaria, relaciones de discriminación y recursos para impedir el avance de las orientaciones transformadoras del proceso político y educativo más general.

Ahora cabe enumerar sumariamente una serie de complejidades que deben constituir un aspecto del balance de esta transformación tan sustantiva que se propicia en la educación venezolana.

Tal y como se señaló en la caracterización de la vieja educación, hay una escuela que reproduce un modelo de cultura escolar consistente con la división social del trabajo capitalista, con los mecanismos de opresión política y las relaciones de negación cultural. Ese esquema se basa en un concepto del conocimiento legítimo y una cierta organización del trabajo pedagógico. La vieja educación se presenta desvinculada de la vida, centrada en la expectativa de la transmisión de conocimientos elaborados por expertos. Se plantea la noción de docente como aplicador de un paquete pedagógico diseñado desde arriba, por afuera y, a menudo, contra los intereses, expectativas y necesidades de educandos y educadores.

La vieja escuela subordina la razón pedagógica a la razón burocrática. Los tiempos, los espacios, los viejos programas, los dispositivos de evaluación y los formularios condicionan la práctica pedagógica que debe adecuarse a esos moldes organizativos. Pervive aún un núcleo de instituciones que "desechan” a quienes más la necesitan bajo la coartada de la teoría de los dones o del rendimiento educativo.

Se verá entonces que el cambio propuesto se constituye en un desafío gigantesco: desmontar la vieja escuela y construir una nueva educación emancipadora.

El proceso en curso es bien interesante, y revela los claroscuros de esta empresa. A nuestro juicio la posibilidad de fundar una educación liberadora está íntimamente ligada a la construcción de otro modelo cultural, político, institucional y productivo. Las fuerzas de la transformación se dirigen a esa dirección y asistimos a una convivencia compleja y contradictoria de lo viejo y lo nuevo.

Aunque no pudimos desplegar la descripción de lo visualizado en el terreno, pudimos ser testigos de avances que registramos en el nivel de algunas instituciones educativas, y de algunos municipios. Estos logros chocan con algunos límites estructurales. Señalaremos algunos de estos obstáculos.

Primero, la dimensión de la subjetividad y la intensa y prolongada batalla cultural que se está librando para construir educación que supere la naturaleza esencialmente injusta de la vieja escuela. Por un lado, una parte significativa de los docentes 
antiguos se resisten a adoptar las nuevas formas de trabajo propuestas, parapetándose tras la defensa corporativa de su título y la disciplina en la que fue formado. Pero no se trata únicamente de ellos. Muchos de los padres siguen esperando de la escuela una calificación numérica que ponga a sus hijos en la senda del éxito evaluativo, más preocupados por la nota que por los aprendizajes efectivamente logrados por muchachas y muchachos. Y, aunque más dúctiles, estudiantes ganados por la lógica meritocrática tardan todavía en adecuarse a un modelo pedagógico cuyo fin no es la legitimación de la desigualdad sino la formación de hombres y mujeres libres, con autonomía de pensamiento, que desarrollen todos los aspectos de su personalidad y comprometidos con un proyecto colectivo de presente y de futuro.

Segundo, el recorrido de la política educativa bolivariana atravesó por cambios en los responsables ministeriales que discontinuaron parte de los procesos previos. En efecto, la Constituyente Educativa elaboró un Proyecto Educativo Nacional que no fue retomado al final de la misma, cuando el Ministro Navarro fue reemplazado por el ministro Istúriz, quién impulsó las Misiones Educativas diseñadas en la gestión anterior. Con la asunción de Adam Chávez se elaboró un Currículun Bolivariano que fue desandado por el cuarto ministro - nuevamente Héctor Navarro - quién avanzó en la sanción de la Ley Orgánica de Educación. Estos procesos no permitieron afianzar con más claridad los cambios en la construcción de una nueva educación pública.

Tercero, constituyó un problema la coexistencia de modos antagónicos de formación docente. En efecto una parte de las instituciones formadoras de docentes - particularmente las Universidades Tradicionales, "autónomas" - se resisten a modificar los planes de estudio. Otras Universidades, agrupadas alrededor de la Misión Sucre y que integran el Programa Nacional de Formación de Educadores, están encarando una formación mucho más alineada con el proceso transformador en las instituciones educativas.Hay una misma complejidad en la actualización docente, pues coexisten postgrados tradicionales con nuevas propuestas de formación vinculada a la práctica.

Cuarto, se produce una tensión compleja entre la regulación del trabajo docente - construida a partir del viejo modelo pedagógico - y las nuevas características del proceso laboral del enseñante.

Como ocurre en todos los aspectos de la vida social, la construcción de una nueva hegemonía está en una tensión sin descanso entre los elementos que impulsan la transformación revolucionaria del orden y aquellos que defienden con uñas y dientes la reproducción del viejo estado de cosas.

El Estado va desplegando dos fuertes líneas directrices para impulsar la transformación. 
Quinto, y en términos de los ámbitos de gobierno, se han realizado análisis muy críticos de los mecanismos de gobierno ministerial y de cada nivel de decisión (Lanz, 2010). Se impulsaron procesos de diagnóstico de los mecanismos de funcionamiento y canales organizativos y se van diseñando procesos transformadores. Dicho camino está en sus inicios y es pronto para sacar conclusiones al respecto.

En términos del desarrollo curricular, se van implementando no sin dificultades mecanismos, dispositivos, relaciones, prácticas y nuevas estructuras que vayan acompañando el cambio en el modelo organizativo de la vieja escuela. Se registran avances sustantivos en la creación de un sentido común y un discurso que resalta una educación liberadora. El tema a profundizar es el grado en que dicho discurso emancipador se traduce en acciones concretas. Los mecanismos de evaluación, de inducción del trabajo colectivo, de las propuestas de planificación integrada, de vinculación con el contexto, de introducción de saberes vinculados a la producción y a la cultura popular, etc., van socavando los cimientos del viejo orden pedagógico y abriendo el paso a una nueva escuela.

Las estrategias utilizadas son variadas, y algunas van revelando un elevado grado de eficacia. Una de ellas es el impulso de modificaciones intrínsecas de las instituciones educativas a partir de procesos de investigación acción acompañadas por las autoridades ministeriales. El impulso se opera desde dentro de cada Escuela o Liceo, y pone en juego tensiones que suponen procesos de cambio lentos y muy trabajosos.

Una segunda es la generación de iniciativas externas a las instituciones que las penetran modificando sus modos de funcionamiento. Algunas de ellas han tenido una existencia acotada en el tiempo, otras se van instalando como dispositivos permanentes. Entre estas últimas destacamos una de carácter nacional y otra aplicada específicamente al Estado de Aragua.

El Programa Todas Las Manos a la Siembra constituye una poderosa novedad que irrumpe en la vida de las instituciones pedagógicas articulando educación, producción y ecología. Todas las instituciones educativas - rurales como urbanas - tienen la exigencia de desarrollar proyectos productivos bajo la perspectiva agroecológica. Y, complementariamente, de imbricar estos procesos formativos con el currículo escolar enriqueciendo, por un lado, la práctica productiva. Por otro, permite abordar desde otro ángulo aquellos conocimientos científicos que suelen enseñarse desvinculados de la realidad concreta. Dicha realidad, entonces, va convirtiéndose en pedagógica.

Los Espacios Permanentes de Desarrollo Cultural Curricular Endógenos (EPEDECUes) en Aragua se desarrollan un día por semana - con la perspectiva de ir ampliando progresivamente el número de días escolares regidos por esta propuesta - en 
los que los estudiantes eligen la actividad de formación. Estas actividades formativas se vinculan a prácticas útiles, y pueden ser productivas, expresivas, culturales entre otras. Convergen estudiantes de distintos años a partir de intereses, necesidades y expectativas comunes. Este espacio de libertad es denominado por los estudiantes como "el día feliz" y se espera que dichos aprendizajes se imbriquen con el currículo escolar de los días "normales". Por caso, un profesor de química enseña tecnología de alimentos a partir de la producción de chupetines. En las clases posteriores de química son retomados los aprendizajes prácticos desarrollados en los Epedecues. Al igual que el Programa Todas las Manos a la Siembra, estos dispositivos van exigiendo novedosos mecanismos de construcción curricular y haciendo surgir, desde los cimientos de la vieja educación, una educación radicalmente democratizadora, participativa, superadora de la fragmentación entre teoría y práctica, entre docentes y estudiantes, entre gobernantes y gobernados.

La evidencia empírica revela elementos de gran complejidad que expresa la transición en Venezuela, que ensaya los caminos para superar el orden capitalista y reemplazarlo por el Socialismo Bolivariano.

En todos los aspectos de la vida social pueden verificarse importantes avances, tensiones estructurales, fuerzas de la conservación pretendiendo obturar los cambios frente a un poder colectivo, popular, que constituye un poderoso motor de las transformaciones en proceso.

No es posible prever el desenlace de este proceso. Las revoluciones sociales del siglo xx han mostrado su capacidad de transformación pero también límites insuperables a la hora de resolver aspectos estructurales y relacionales heredados del orden capitalista. Venezuela avanza aceleradamente en la transformación del orden social, generando inéditas invenciones negadoras de las injusticias del capitalismo heredado. Y junto a esos logros, asistimos a la coexistencia de tendencias conservadoras, contradicciones en las fuerzas propias, y errores propios de la invención de nuevas prácticas. El momento histórico es de un gran peligro, pero también de una gran posibilidad. La Venezuela Bolivariana no escribió todavía su última palabra.

\section{Notas}

1. Se entiende como Iv República el vigente en el período histórico abierto en 1958 con el denominado Pacto de Punto Fijo - acuerdo bipartidista entre el socialdemócrata Acción Democrática y el Social Cristiano copei (Comité de Organización Política Electoral Independiente) - y su finalización con la elección de Hugo Chávez Frías como presidente en 1998.

2. Paralelamente se desarrolló una Asamblea Constituyente que alumbró la nueva Constitución de la República Bolivariana de Venezuela.

3. El punto de partida fue la Misión Robinson en 2003, que apuntó a la superación del analfabetismo (logrado según unEsco en 2005) y la finalización de la educación primaria. Luego se fueron 
implementando sucesivas Misiones: Ribas (para el nivel secundario) y Sucre (para el nivel universitario). En todos los casos se expresó un nivel inédito de expansión educativa, asegurando procesos de democratización del acceso a la educación.

4. Entrevista colectiva a docentes.

5. Concretamente, desde el inicio del proceso político bolivariano se desarrollan en las ciudades ámbitos colectivos - llamadas Mesas temáticas - en las que se comenzaron a debatir e implementar proyectos gestionados directamente por los pobladores como, por ejemplo la Mesa del agua. A partir de la necesidad concreta y su abordaje colectivo en el territorio, el Estado comenzó a proveer asistencia técnica y financiamiento para asegurar la adecuada gestión de aquellas iniciativas que permitiesen canalizar la demanda. De esas experiencias surgieron como salto organizativo los Consejos Comunales como ámbitos de participación autogestionados en los Municipios. Se trata de mecanismos de participación y modos de funcionamiento territoriales para la implementación de proyectos que surgen de la participación comunitaria en función de necesidades e intereses colectivos. De esas estructuras se deriva la creación de las Comunas, definidas como unidades locales integrales para la construcción del socialismo. Es decir que se pasa de formas que parten de necesidades perentorias y puntuales a mecanismos de organización que van desplegando una planificación estratégica desde una concepción de democracia sustantiva.

6. El término "brutal" puede fundarse en diversas evidencias pasadas y presentes, a saber: el fallido intento del golpe de Estado de abril de 2002 en el que el presidente Chávez estuvo virtualmente secuestrado; el paro petrolero que generó un inédito desquicio productivo a fines de ese mismo año; el boicot de la oposición política a las elecciones de 2005; la sistemática labor destituyente de los medios de comunicación hegemónicos o las provocaciones de una parte del movimiento estudiantil universitario como punta de lanza de los sectores golpistas y conservadores, entre otros indicadores.

7. Plan Nacional Simón Bolívar. Líneas Generales de Desarrollo Económico y Social de la Nación 2007-2013. Ministerio de Educación Popular para la Comunicación y la Información, Caracas, Venezuela, p. 3

8. La responsabilidad estatal se reafirma en el artículo 5o sostiene que "El Estado docente es la expresión del Estado en Educación, en cumplimiento de su función indeclinable y de máximo interés como derecho humano universal y deber social fundamental, inalienable, irrenunciable, y como servicio público que se materializa en las políticas educativas".

9. Ver artículos 6, numeral 2, incisos e), f), g), h), k); $14^{\circ}, 22^{\circ}, 41^{\circ}$ y otros.

10. Ley Orgánica de Educación, artículo 15, inciso 9.

11. El punto sobre las universidades tradicionales y la formación docente amerita avanzar en un profundo estudio sistemático. En nuestra aproximación al campo pudimos percibir un proceso de transición complejo en el que algunas de las instituciones formadoras continúan con el viejo modelo de formación docente, a contramano de las mutaciones profundas que se están desarrollando en el resto del sistema educativo formal. Hoy hay instalado un debate sobre una nueva Ley de Educación Universitaria que, de prosperar, será la antesala de profundos cambios institucionales en las universidades tradicionales.

12. Dice la última parte del artículo $40^{\circ}$ que "una ley especial regulará la carrera docente y la particularidad de los pueblos indígenas".

\title{
Referencias
}

\author{
BAUDELOT, C.; ESTABLET, R. La escuela capitalista. 13. ed. México, DC: Siglo xxI, \\ 1999. \\ BOURDIEU, P.; PASSERON, J.C. La reproducción: elementos para la teoría del sistema \\ de enseñanza. 3. ed. México, DC: Fontamara, 1998.
}


CAPELLA, J.R. Los ciudadanos siervos. Madrid: Trotta, 2005.

FRASER, N. Reconsiderando la esfera pública: una contribución a la crítica de la democracia existente. Entrepasados, Buenos Aires, v. 4, n. 7, p.87-114, 1994.

GRAMSCI, A. La alternativa pedagógica. 5. ed. México, DC: Fontamara, 1998.

HOLLOWAY, J. Del grito de rechazo al grito de poder: la centralidad del trabajo. In: Bonnet, A.; Holloway, J.; Tischler, S. (Comp.). Marxismo abierto: una visión europea y latinoamericana. Buenos Aires: Universidad Autónoma de Puebla y Herramienta, 2005. v. 1.

IMEN, P. La escuela pública sitiada: crítica de la transformación educativa. Buenos Aires: Ediciones del ccc, 2005.

IMEN, P. La escuela pública tiene quién le escriba: Venezuela, Bolivia, y sus nuevas orientaciones político educativas. Buenos Aires: Ediciones del ccc, 2010.

LANZ, C. Memoria histórica e innovación pedagógica: a propósito de la sistematización del Proyecto Educativo Integral Comunitario. Caracas: Ministerio del Poder Popular para la Educación, 2009.

LANZ, C. Sistematización de la Jornada de Evaluación de la Gestión en el Ministerio del Poder Popular para la Educación. Caracas: Ministerio del Poder Popular para la Educación, 2010.

LOWY, M. Walter Benjamín: aviso de incendio; una lectura de las tesis "Sobre el concepto de historia. Buenos Aires: Fondo de Cultura Económica, 2005.

PONCE, A. Educación y lucha de clases. 4. ed. México, DC: Mexicanos Unidos, 1981.

RODRÍGUEZ, S. O inventamos o erramos. Caracas: Monte Ávila, 2008.

URDANETA, M. Ahora Venezuela es otra y es de todos. Círculo Bolivariano de Holanda. (Nederlandse solidariteit met de Bolivariaanse Revolutie). Disponible en: $<$ www.circulobolivariano.nl/.../553-ahora-venezuela-es-otra-y-es-de-todos $>$. Acesso em: 15 jan. 2011.

VENEZUELA. Ministerio del Poder Popular para la Educación Universitaria. Logros de la Revolución Socialista bolivariana en Educación Universitaria: 1999-2010. Caracas: Educación Universitaria Socialista Bolivariana, 2011.

Recebido em março de 2011.

Aprovado em maio de 2011. 